\title{
CULTURA E CLIMA ORGANIZACIONAL: INFLUÊNCIA NA QUALIDADE DE VIDA NO TRABALHO
}

\author{
https://dx.doi.org/10.48097/2674-8673.2021n5p04
}

\author{
Fabiana Jéssica Prado Lins ${ }^{1}$ \\ Jéssica Renata Gomes Santos ${ }^{2}$ \\ João Biron de Oliveira Filho ${ }^{3}$ \\ Eronildo Ferreira do Carmo ${ }^{4}$
}

\section{RESUMO}

O objetivo principal deste estudo foi compreender a influência que a cultura e o clima organizacional das empresas podem ter em relação às doenças ocupacionais de seus colaboradores como, por exemplo, estresse, ansiedade, depressão, síndrome de burnout, entre outras. Buscou-se também compreender quais os principais fatores que na percepção dos colaboradores causam um clima organizacional negativo. A pesquisa foi bibliográfica e de campo. Para coleta dos dados foi utilizado, como principal ferramenta, um questionário fechado. Foi possível comprovar que as empresas que adotam medidas que visam melhorar a qualidade de vida do trabalhador podem ter um índice maior de colaboradores engajados, motivados e produtivos, enquanto as empresas que não investem nessa área consequentemente tendem a um índice elevado de colaboradores doentes por esses fatores.

Palavras-chave: Cultura organizacional. Clima organizacional. Doenças ocupacionais.

Data de submissão: $05 / 05 / 2021$

Data de aprovação: $31 / 05 / 2021$

\begin{abstract}
The main objective of this study was to understand the influence that the culture and organizational climate of companies can have in relation to occupational diseases of their employees, such as, for example, stress, anxiety, depression, burnout syndrome, among others. We also sought to understand what are the main factors that, in the perception of employees, cause a negative organizational climate. The research was bibliographic and field.

\footnotetext{
${ }^{1}$ Concluinte do curso de Pós-graduação em Psicologia Organizacional e do Trabalho - FMGR.

E-mail: fabianapradolins@gmail.com

${ }^{2}$ Concluinte do curso de Pós-graduação em Psicologia Organizacional e do Trabalho - FMGR.

E-mail: jessicarenatasantos@gmail.com

${ }^{3}$ Professor orientador do curso de Pós-graduação em Psicologia Organizacional e do Trabalho - FMGR.

E-mail: joaobiron@metropolitana.edu.br

${ }^{4}$ Professor coorientador do curso de Pós-graduação em Psicologia Organizacional e do Trabalho - FMGR.

E-mail: proferon100@gmail.com
} 
For data collection, a closed questionnaire was used as the main tool. It was possible to prove that companies that adopt tools that aim to improve the quality of life of workers can have a higher rate of engaged, motivated and productive employees, while companies that do not invest in this area consequently tend to a high rate of sick employees due to these factors.

Keywords: Organizational culture. Organizational climate. Occupational diseases.

\section{INTRODUÇÃO}

Analisar e compreender quais são os fatores que causam doenças ocupacionais é algo fundamental para as empresas nos dias atuais, pois a saúde, o bem-estar, a integridade física e mental do colaborador refletem no seu rendimento no trabalho.

O estresse no ambiente corporativo sempre existiu. A diferença é que nos dias de hoje a consciência de seus efeitos são muito maiores e mais complexos. A qualidade de vida no trabalho tem sido cada vez mais discutida após estudos comprovarem os efeitos positivos que um bom clima organizacional gera tanto aos colaboradores quanto às organizações. $\mathrm{O}$ objetivo do presente estudo é apontar os principais fatores relacionados com o estresse nas organizações bem como programas que podem auxiliar na redução dos mesmos.

\section{REFERENCIAL TEÓRICO}

Neste item são abordadas as bases conceituais sobre cultura e clima organizacional, e sua influência na qualidade de vida do trabalhador sobre os aspectos saúde $\mathrm{x}$ doença, bem como exemplos práticos sobre os temas citados, de modo a facilitar a articulação entre referências e realidade de campo.

\section{Cultura organizacional}

O termo cultura organizacional, que também é conhecida como cultura corporativa, é um termo da administração contemporânea usado para se referir ao conjunto de crenças, missão, valores e políticas internas de uma empresa. Para Schein (2009):

Cultura organizacional é um fenômeno dinâmico que nos cerca em todas as horas, sendo constantemente desempenhada e criada por nossas interações com outros e moldada por comportamento de liderança, e um conjunto de estruturas, rotinas, regras e normas que orientam e restringem $\mathrm{o}$ comportamento. (SCHEIN, 2009, p. 01).

Robbins (2012, p. 501) define cultura como "um sistema de valores compartilhado pelos membros de uma organização que a diferencia das demais.” Desse modo, observa-se que para 
os autores a cultura de uma empresa é caracterizada através do comportamento coletivo e social dos funcionários a partir de princípios propostos pela organização em que fazem parte.

Nessa mesma linha de pensamento Siqueira (2012, p. 331) cita que os valores organizacionais são elementos estruturantes, constituindo padrões coletivos que norteiam o trabalho e o cotidiano nas empresas, os quais devem se subordinar aos valores pessoais dos membros organizacionais.

Dessa forma, cada organização terá uma cultura organizacional distinta, decorrente das diferentes normas, crenças, regras e relações que ocorrem em cada uma delas, e por ter o poder de mudar o rumo da organização a mesma deve manter uma cultura enraizada nos seus princípios e ao mesmo tempo flexível, devendo estar sempre atenta aos acontecimentos tecnológicos e preocupada com a gestão de pessoas.

Assim, a cultura organizacional mostra-se um fator de extrema importância para as empresas, pois além de servir como um guia para alinhar os comportamentos dos funcionários no dia a dia de trabalho, a mesma pode contribuir tanto para a construção de uma identidade organizacional positiva quanto uma imagem negativa como um todo, além de influenciar diretamente no clima da organização.

\section{Clima organizacional}

O termo clima organizacional é usado para se referir à percepção coletiva que os funcionários de uma empresa têm sobre a organização. Por esse motivo ele é um dos maiores indicadores do estado de ânimo individual e geral dos membros da corporação.

Luz (2012, p. 20) afirma que o clima organizacional pode ser afetado por fatores externos (condições de saúde, habitação, lazer e família) ou pelas próprias condições sociais dos colaboradores, ou seja, dentre os diversos fatores que podem alterar o clima de uma organização, o mais comum é que seja afetado por sua cultura.

Por esse motivo é de fundamental importância que os gestores, líderes imediatos e os profissionais de Recursos Humanos estejam sempre atentos a isto, pois é a partir dessa percepção do clima da organização e dos fatores que o influenciam que poderão tomar decisões assertivas para garantir um cenário de trabalho mais saudável.

Segundo Srour (2012) é importante ressaltar que os conceitos de cultura e de clima organizacional não são intercambiáveis, ou seja, o clima não apanha os modos institucionalizados de agir e de pensar, pois seu eixo consiste em capturar a "temperatura social" que prevalece na organização. E além do fator cultural organizacional, existem diversos aspectos que também influenciam no clima organizacional. Há um conjunto de 
fatores que são divididos em: psicológicos, físicos, sociais, de comunicação e econômicos (DIAS, 2013).

\section{Fatores psicológicos}

São constituídos pela soma de todos os elementos que podem ou não motivar o indivíduo, entre eles: a motivação, que pode ser definida como a vontade que o colaborador tem para realizar os esforços necessários para alcançar as metas da organização; o nível de satisfação, que se refere ao grau de concordância entre expectativas de recompensa e o que está recebendo concretamente; a estabilidade funcional, que ocorre quando as mudanças de postos tanto horizontal quanto vertical não são realizadas com transparência; e segurança no emprego, quando a empresa passa por períodos de instabilidade e não informam rapidamente os passos que tomará ou as mudanças que ocorrerão, criando um clima de boatos e insegurança nos funcionários, desmotivando-os.

\section{Fatores físicos}

Dentre os fatores físicos há a disposição do espaço, que se refere à distância entre as pessoas e as instalações, o que pode exercer uma forte influência na interação social; o tamanho da organização, pois a distância que separa os departamentos e setores gera maior ou menor proximidade das pessoas e altera o clima; a iluminação, que em um ambiente de trabalho influi na execução das tarefas, pois contribui para melhor visualização dos objetos e leitura; e o ruído, já que em um ambiente de trabalho com altas doses de ruídos facilita a ocorrência de erros devido à falta de concentração.

\section{Fatores sociais}

Dentre os fatores sociais destacam-se o papel do fundador, pois a presença do mesmo no ambiente de trabalho pode atrapalhar o rendimento, pois suas atitudes e opiniões passam a ser referência; os estilos de liderança, já que nos diversos níveis hierárquicos uma liderança estável dá segurança à equipe que lidera e um líder instável provoca instabilidade e desmotivação na equipe; e o grupo dominante, pois em toda organização há um grupo que constitui referência e pode ser formado por dirigentes ou até mesmo um grupo informal que tem domínio no que faz. 


\section{Fatores de comunicação}

É uma maneira de conhecer as ideias, fatos, pensamentos, sentimentos e valores dos outros. É importante que haja uma comunicação efetiva nas organizações. Caso não ocorra pode haver um desequilíbrio na equipe de trabalho. As novas tecnologias (celulares, internet, etc.) permitem que se estabeleçam novas formas de comunicação, dessa forma o contato pode ser mais efetivo, facilitando o acesso dos postos mais baixos na escala hierárquica com os dirigentes.

\section{Fatores econômicos}

Quando a remuneração não é adequada ou quando ocorre com atrasos frequentes gera um clima contínuo de instabilidade e insatisfação. O pagamento pelo bom empenho, tanto individual quanto em equipe, gera um ambiente competitivo positivo onde o mérito é valorizado. Os aumentos periódicos e o recebimento de prêmios por mérito é fundamental para um bom desempenho, pois tendem a criar um ambiente positivo e valorizado pelos funcionários.

\section{Qualidade de vida no trabalho: saúde $X$ doença}

Pode-se definir a qualidade de vida no trabalho como um conjunto de fatores que colaboram para o bem-estar físico e emocional dos funcionários de uma empresa. Segundo Sant'Anna e Kilimnik (2011):

Foi com a revolução industrial e a sistematização dos métodos de produção, nos séculos XVII e XIX, que as condições de trabalho e sua influência sobre a produção e a moral dos trabalhadores passaram a ser estudadas de forma científica. (SANT'ANNA \& KILIMNIK, 2011, p. 3).

Atualmente é notório que a qualidade de vida no trabalho tem grande influência do clima organizacional, pois os funcionários passam grande parte de seu dia na empresa. Por esse motivo é essencial que os mesmos sintam-se à vontade para exercerem suas atividades da melhor maneira possível.

Os líderes devem se atentar às situações acerca da organização, pois o que pode parecer produtividade para a chefia imediata, o colaborador pode estar tendo a percepção de pressão e demanda demasiadamente intensa. Essa busca do equilíbrio entre as necessidades, expectativas e recursos que o trabalhador possui, as necessidades, expectativas e demandas das organizações têm sido um desafio para a humanidade. (ZANELLI, 2010). 


\section{Estresse ocupacional}

Quando o organismo se encontra numa posição de perigo são mobilizados recursos fisiológicos que o prepara para o enfrentamento através de diversos mecanismos de defesa.

A esse respeito Cosenza (2021) afirma que:

o estresse agudo, portanto é um bom estresse, que nos mobiliza para enfrentar situações significativas. Porém se essas situações se prolongam, tem origem o estresse crônico, um fenômeno que causa desequilíbrio, patologias e tem repercussão até na longevidade. (COSENZA, 2021, p. $4)$.

O estresse relacionado ao ambiente de trabalho, sem dúvidas, gera um impacto na saúde física e mental do trabalhador e pode dar origem a vários problemas psicológicos como dores de cabeça, irritabilidade, alterações do sono, ansiedade, dificuldades de concentração e de tomada de decisão, sintomas depressivos ou até mesmo quadros psiquiátricos, como por exemplo, depressão, síndrome de burnout e Distúrbio de Stress Pós-traumático (D.S.P.T.).

Dentre as doenças mais relacionadas ao mau clima organizacional, o estresse é a mais comum e está relacionada a uma das doenças mais preocupantes ao bem-estar do colaborador. Este tipo de doença pode acarretar danos à saúde física e mental, assim prejudicando o desempenho nas atividades exercidas.

Fiorelli (2007) ressalta que pequenos problemas que ocorrem no dia a dia, gerando aborrecimentos diários, que por vezes parecem insignificantes, se acumulados, acabam gerando uma fonte de estresse. Sendo assim, é importante se atentar a essas pequenas coisas que se tornam rotineiras e que podem até parecer inofensivas, como a distribuição desigual das atividades por parte dos gestores, o que acaba gerando sobrecarga para alguns; metas inalcançáveis, que causam trabalho excessivo e desgaste físico e mental, sem chances de alcançar o resultado desejado; a falta de colaboração entre os membros da equipe; má relação com a chefia; falta de feedback positivo; sentimento de desvalorização ou remuneração incompatível com a função; falta de flexibilidade, etc. Essas entre outras ações do dia a dia podem contribuir para o aumento do nível de estresse, pois o profissional pode até não perceber de imediato, mas com o passar dos dias ele tende a se sentir mais desmotivado e estressado com a rotina de trabalho, podendo esses acontecimentos levar ao mais alto nível de estresse no futuro.

\section{Consequências do estresse}

Para Fiorelli (2007), as fontes de pressão do estresse podem manifestar diversos sintomas nas pessoas, tanto no nível pessoal (dor nos ombros e coluna, depressão, aumento da 
pressão arterial, irritabilidade acentuada, dentre outros) como organizacional (absenteísmo, rotatividade, queda na qualidade da produção, dentre outros). Tais sintomas podem acarretar nas pessoas o desenvolvimento de patologias físicas e mentais, como problemas do coração, úlcera, gastrite, esgotamento, etc. Outra condição relacionada a todos os outros fatores citados anteriormente é o a síndrome de burnout. O termo vem do inglês e numa tradução livre significa queimar. Segundo o Dicionário Online de Português (2019) é definido como um distúrbio psíquico ocasionado pelo excesso de trabalho, sendo capaz de levar alguém à exaustão extrema, ou seja, um grau de estresse generalizado e esgotamento físico. Esse termo é exclusivamente ligado à vida profissional, a esse sofrimento que está diretamente ligado ao mau clima organizacional, como por exemplo: cobranças excessivas vindas da chefia, estabelecimento de metas inalcançáveis, assédio moral vindo dos gestores, ou até mesmo bullying praticado por pessoas do mesmo nível hierárquico; sem falar nas fofocas que geram intrigas entre os colaboradores e a falta de espaço para ser ouvido. Esses entre outros fatores podem gerar o sofrimento do trabalhador, que nasce por consequência das relações de trabalho e a partir da cultura organizacional.

As organizações podem adotar algumas intervenções que permitem ajudar os profissionais a gerir o stress, a prevenir ou minimizar o burnout e a promover o bem-estar: oferecer condições favoráveis para o trabalho (ambiente físico adequado - iluminação, ventilação, limpeza, organização); realizar treinamentos constantes para os gestores de como gerir um bom clima organizacional; observar como andam as relações de trabalho para eliminar a relação abusiva entre supervisores e subordinados, se houver; evitar longas horas de trabalho e ciclos ininterruptos; e incentivar e oferecer programas de qualidade de vida. Estas são algumas das medidas que podem ser adotadas pelas organizações.

\section{METODOLOGIA}

Este artigo foi elaborado com o objetivo de apresentar os benefícios que as empresas e seus colaboradores podem ter ao cultivar um bom clima organizacional, bem como ressaltar as doenças ocupacionais e outros pontos negativos que o mau clima de uma organização pode gerar para ambos. Neste trabalho, especificamente, pretende-se:

a) Identificar os principais fatores que se relacionam ao mau clima organizacional, podendo gerar danos psicológicos e financeiros aos colaboradores e às empresas;

b) Compreender as principais medidas que podem ser tomadas pelas empresas para diminuir o estresse, cultivar um bom clima organizacional e manter os funcionários 
motivados e produtivos.

A pesquisa foi bibliográfica e de campo, focada numa análise propositiva, na forma qualitativa, dividida em três etapas. Na primeira foi realizada a revisão bibliográfica sobre cultura e clima organizacional, buscando a definição da base conceitual em livros. A segunda consistiu em realizar uma pesquisa de campo para coleta dos dados, que utilizou como principal ferramenta um questionário semiaberto. E a terceira etapa consistiu em relacionar o referencial teórico com os dados obtidos na pesquisa de campo para realizar uma análise crítica entre teoria e prática.

Em decorrência da pandemia de COVID-19 a pesquisa de campo foi realizada de forma 100\% online, através de um questionário do Google Forms, e enviado por e-mail ou WhatsApp para um total de 80 pessoas. A pesquisa esteve focada na percepção do clima organizacional pela visão dos colaboradores diante de suas realidades no dia a dia de trabalho e não na empresa como um todo. Os participantes têm faixa etária entre 25 e 55 anos e exercem cargos operacionais numa empresa privada, do ramo de serviços logísticos, que fica localizada no centro do Cabo de Santo Agostinho, cidade do estado de Pernambuco. A empresa foi denominada Transportadora Alfa (nome fictício) para preservar a identidade da instituição.

\section{ANÁLISE DA PESQUISA DE CAMPO}

1- Você acha que sua equipe de trabalho cultiva um bom clima organizacional? 80 respostas

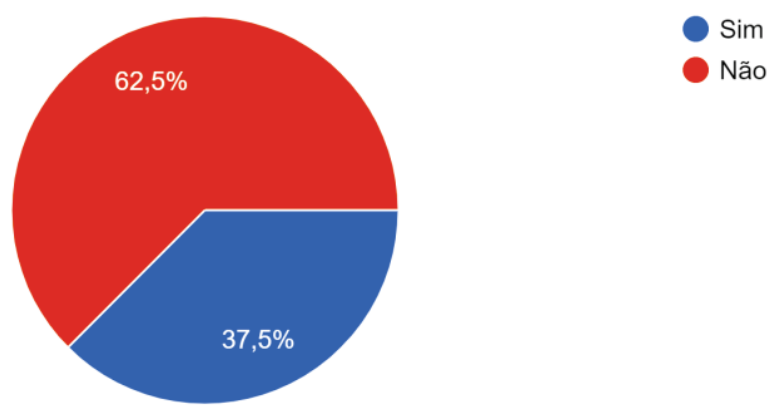

Vimos, através da pesquisa bibliográfica, que quando existe um bom clima organizacional as pessoas trabalham mais satisfeitas, no entanto, quando esse clima é tenso, torna os colaboradores preocupados, insatisfeitos. Entre os participantes da pesquisa 50 
responderam que sua equipe não cultiva um bom clima organizacional, e os outros 30 participantes responderam que o bom clima é cultivado na equipe.

2-Os funcionários são tratados com respeito independente do cargo?

80 respostas

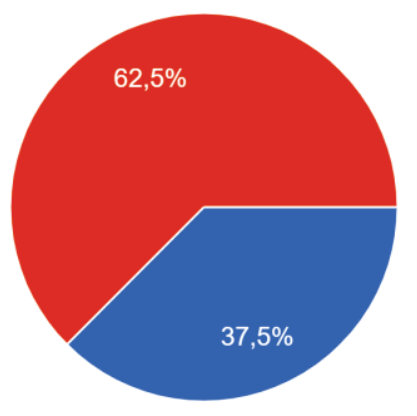

Sim

Não

Neste resultado, observa-se que na percepção dos participantes os colaboradores não recebem um tratamento igualitário independentemente do cargo. Isso não deve acontecer, pois é fundamental que os líderes e liderados de uma empresa tenham ciência de que todos os cargos são importantes dentro de uma organização, e todos devem ser tratados de maneira igualitária.

3- Na empresa em que trabalha, as pessoas mais competentes têm as melhores oportunidades? 80 respostas

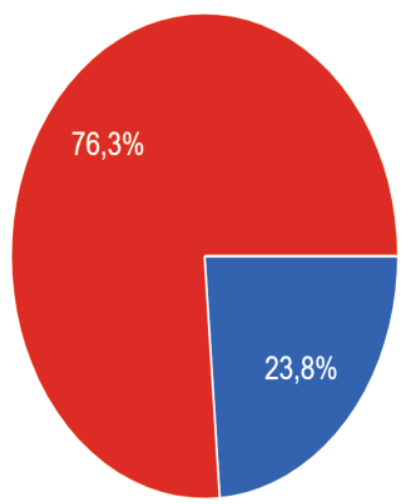

Como é perceptível no gráfico, a maioria dos entrevistados não acham que os colaboradores mais competentes têm melhores oportunidades. Esta pode ser uma demonstração de insatisfação. 
4- Existe cooperação entre os diversos setores da empresa?

80 respostas

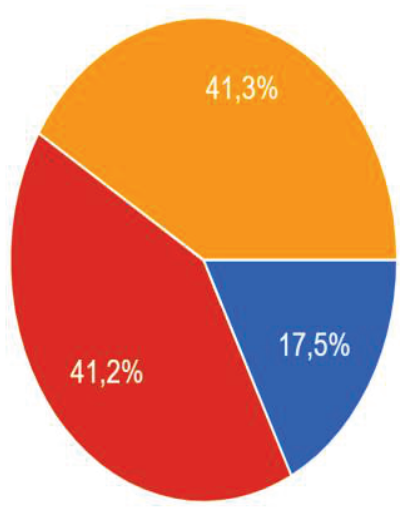

$\operatorname{Sim}$

Não

As vezes

Observamos que, na percepção dos entrevistados, a cooperação entre os diversos setores de suas respectivas empresas está deixando a desejar, pois 33 dos participantes disseram que não há cooperação, enquanto outros 33 disseram que apenas às vezes, e apenas 14 disseram que a cooperação é efetiva.

5- Você acredita que seu trabalho é avaliado de forma justa pelos seus gestores? 80 respostas

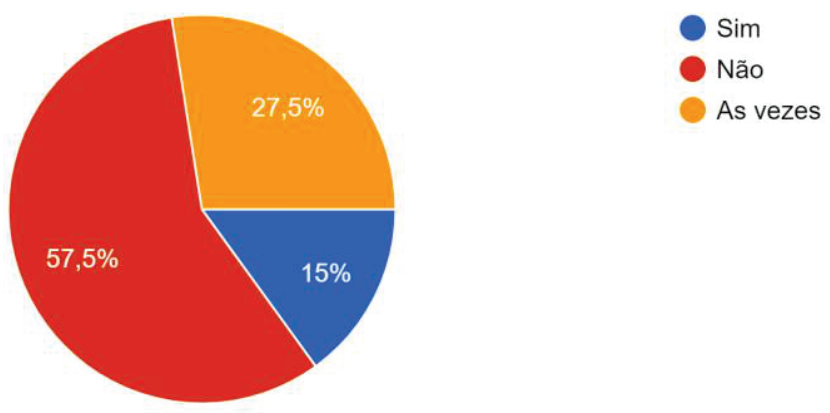

No gráfico acima verificamos que na maioria das vezes os colaboradores não têm seus esforços reconhecidos. 
6- Você recebe o reconhecimento devido quando faz um bom trabalho?

80 respostas

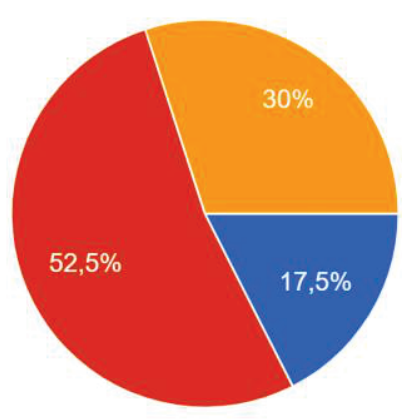

Sim

Não

As vezes

Neste gráfico é possível observar a insatisfação dos colaboradores que participaram da pesquisa ao sentir que seus esforços não são valorizados quando realizam um bom trabalho.

7- Seu gestor exerce pressão sobre seu ritmo de trabalho?

80 respostas

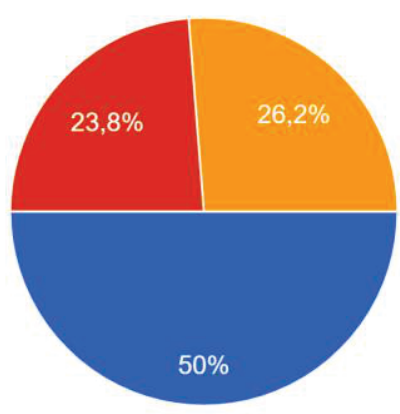

Cinquenta por centos dos participantes afirmam que trabalham sob pressão da chefia, enquanto os outros $26 \%$ relatam que às vezes se sentem pressionados. Apenas $23,8 \%$ não se sentem pressionados. 
8-Já sentiu que deixou seus problemas de trabalho interferirem na sua vida pessoal?

81 respostas

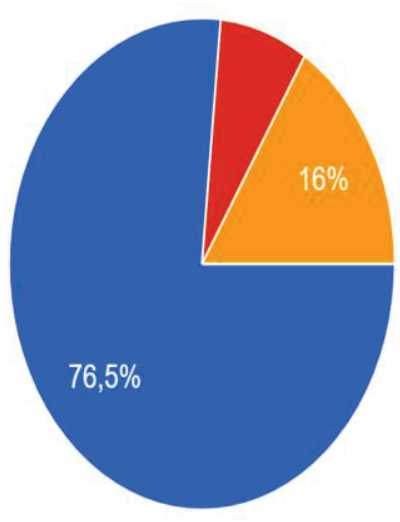

Sim

Não

As vezes

O gráfico acima mostra que $76,5 \%$ já deixaram os problemas de trabalho afetar sua vida pessoal de alguma forma.

10- Você acredita que o estresse causado no ambiente de trabalho pode prejudicar seu desempenho e rendimento profissional.

80 respostas

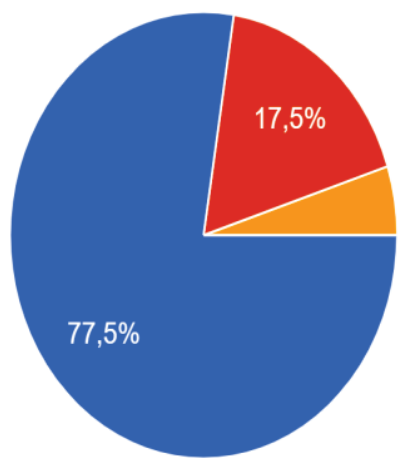

Sim, muito!

Nem tanto.

Não prejudica.

Observamos que a maioria dos participantes acredita que o estresse causado no ambiente de trabalho prejudica o rendimento de suas atividades laborais. 
11- A que fator você relaciona seu estresse no trabalho?

80 respostas

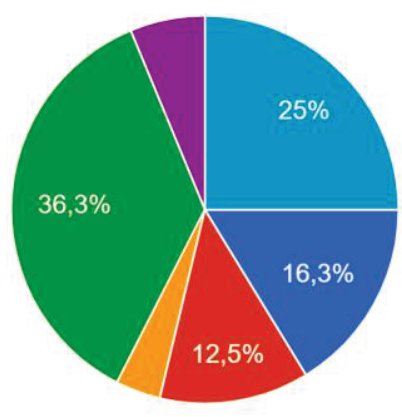

Mau clima organizacional

Salário a baixo da média

Má relação com a chefia.

Sentimento de desvalorização.

Metas inalcançáveis

Outros

Verificamos no gráfico acima que, para os participantes, o fator mais relacionado ao estresse no trabalho é o sentimento de desvalorização. 16,3\% relacionam o estresse ao mau clima organizacional. $12,5 \%$ se sentem estressados por salários abaixo da média, entre outros.

12- Escolha uma das alternativa que você acredita que melhoraria sua qualidade de vida no trabalho?

80 respostas

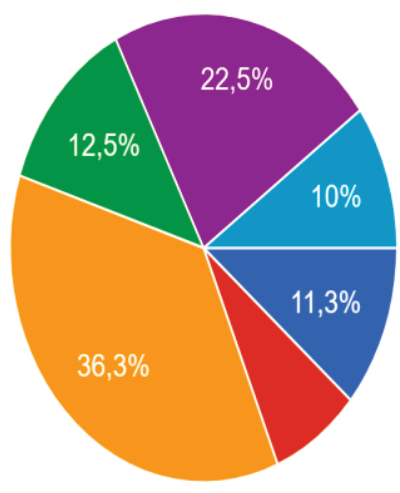

Flexibilidade de horário

Metas reais(atingiveis)

Programas de reconhecimento

Liderança horizontal (aproxima as pessoas e proporciona uma maior integração entre líderes e liderados)

Salário Mais alto

Outros

Quando questionados sobre melhorias na qualidade de vida no trabalho $36,3 \%$ apontaram para a necessidade de programas de reconhecimento. $22,5 \%$ citaram como melhoria a oferta de salários mais altos. Para 12,5\% uma liderança com maior interação com os liderados seria uma indicação de melhora. 11,3\% apontaram a flexibilidade de horário, e 10\% outros. 
13- Já precisou fazer uso de medicamentos para problemas relacionados ao estresse no trabalho? 80 respostas

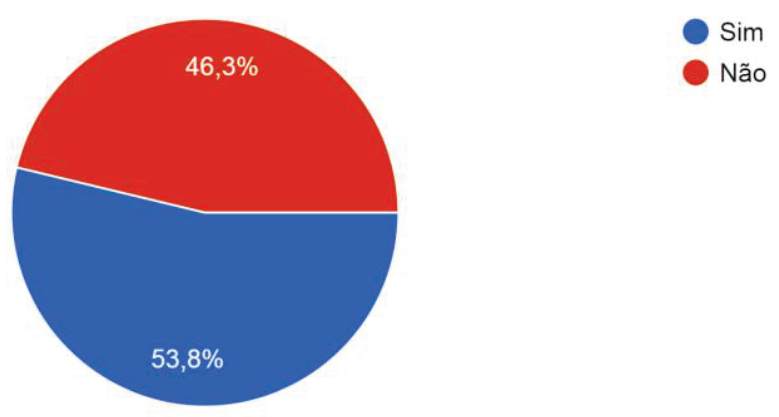

O gráfico acima mostra que mais da metade dos pesquisados já fizeram uso de medicamentos para problemas relacionados ao estresse no trabalho.

\section{4 - Se sim, para qual problema?}

$\mathrm{R}=$ Os remédios mais citados nessa questão aberta foram para as seguintes condições de saúde: dores de cabeça, enxaqueca, dores no corpo e pescoço, ansiedade. Alguns relataram que já necessitam de remédios para quadros de saúde mais agravados como: gastrite nervosa, calmantes e hipertensivos.

15- No geral, você está satisfeito com o clima organizacional da sua empresa?

80 respostas

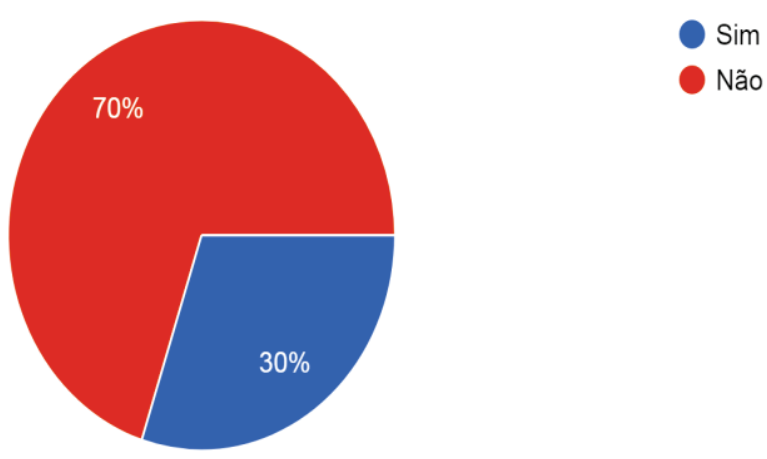

Visualizando o gráfico, fica claro que o índice de insatisfação dos participantes desta pesquisa está mais elevado que os de colaboradores satisfeitos com suas empresas. 56 estão insatisfeitos e apenas 24 satisfeitos com o clima organizacional de seus empregos atuais. 


\section{CONSIDERAÇÕES FINAIS}

Através do estudo bibliográfico e de campo, constatou-se que a cultura organizacional e liderança de uma empresa influenciam diretamente no clima organizacional da mesma, assim como o clima organizacional está diretamente ligado ao bem estar dos colaboradores, a vontade dos mesmos permanecerem por mais tempo no local e a sua produtividade. Através da pesquisa confirmou-se também que altos níveis de estresse causado pelo mau clima podem ocasionar perdas no desempenho profissional e queda na produtividade dos colaboradores, ocasionando doenças ocupacionais e turnover, enquanto as empresas que investirem em qualidade de vida podem gerar o efeito contrário, ou seja, um ambiente de trabalho saudável e favorável, aumento do desempenho e da produtividade, além de diminuir a rotatividade de funcionários.

Através dos resultados obtidos na pesquisa de campo os principais motivos que causam a insatisfação no trabalho para o grupo de pessoas pesquisadas neste trabalho são: falta de colaboração entre a equipe de trabalho e entre os setores; sentimento de desvalorização; falta de tratamento e oportunidades de forma isonômica; mau clima organizacional; excesso de pressão no ritmo de trabalho; e salários abaixo da média.

Diante do problema apresentado sugerimos algumas medidas que podem ser tomadas para construir um ambiente de trabalho saudável:

Investir na capacitação da liderança é primordial, pois bons líderes auxiliam na construção de um ambiente de trabalho saudável, enquanto os líderes mal capacitados podem adoecer a equipe. Outro fator importante para essa questão seria criar uma cultura de valorização dos profissionais através de feedback positivo para reconhecer um bom trabalho realizado. Deve-se adotar um programa de carreiras para proporcionar o crescimento vertical dos trabalhadores que se destacam por seu bom desempenho. É aconselhável trabalhar com metas realistas para evitar sobrecargas e frustrações, além de aderir a um tratamento igualitário nas relações de trabalho independentemente do cargo ou nível hierárquico dos colaboradores.

É preciso entender que só elogios não são suficientes para reter talentos, portanto, é interessante estabelecer recompensas financeiras atrativas, sejam através de um salário de mercado competitivo, de programas de incentivo como promoções, bonificações em dinheiro ou premiações que têm como principal objetivo reconhecer, estimular e retribuir o engajamento e o desempenho dos colaboradores e das equipes de trabalho, além de contribuir para a retenção dos talentos e melhora do clima organizacional. 


\section{REFERÊNCIAS}

CHIAVENATO, Idalberto. Gestão de pessoas: o novo papel dos recursos humanos nas organizações. Rio Janeiro: Elsevier, 1999.

COSENZA, M. Ramon. Neurociência e mindfulness: meditação, equilíbrio emocional e redução do estresse. Porto Alegre: Artmed, 2021.

DIAS, Reinaldo. Cultura Organizacional: Construção, Consolidação e Mudanças. São Paulo: Atlas, 2013.

DICIO. Dicionário Online de Português. Porto: 7 Graus, 2019. Disponível em: https://www.dicio.com.br/burnout/. Acesso em: 30 abr. 2021.

FIORELLI, José Osmir. Psicologia para administradores. Integrando Teoria e Prática. 5. ed. São Paulo: Atlas, 2007.

LUZ, Ricardo. Gestão do clima organizacional. Rio de Janeiro: Qualitymark, 2012.

ROBBINS, Stephen P.; SOBRAL, Filipe. Comportamento organizacional. 14. ed. São Paulo: Prentice-Hall, 2012.

SANT'ANNA, Anderson de Souza; KILIMNIK, Zélia Miranda. Qualidade de vida no Trabalho: Abordagens e Fundamentos. Rio de Janeiro: Elsevier, 2011.

SCHEIN, Edgar H. Cultura organizacional e liderança. São Paulo: Atlas, 2009.

SIQUEIRA, Mirlene Maria Matias. Medidas do Comportamento Organizacional. São Paulo: Artmed, 2012.

SROUR, Robert Henry. Poder, cultura e ética nas organizações. 3. ed. Rio de Janeiro: Elsevier, 2012.

ZANELLI, José Carlos. Estresse nas organizações de trabalho: compreensão e intervenção baseadas em evidências. Porto Alegre: Artmed, 2010. 


\section{APÊNDICE A - Pesquisa de Clima Organizacional aplicada aos entrevistados}

1- Você acha que sua equipe de trabalho cultiva um bom clima organizacional?

2- Os funcionários são tratados com respeito independente do cargo?

3- Na empresa em que trabalha, as pessoas mais competentes têm as melhores oportunidades?

4- Existe cooperação entre os diversos setores da empresa?

5- Você acredita que seu trabalho é avaliado de forma justa pelos seus gestores?

6- Você recebe o reconhecimento devido quando faz um bom trabalho?

7- Seu gestor exerce pressão sobre seu ritmo de trabalho?

8- Já sentiu que deixou seus problemas de trabalho interferirem na sua vida pessoal?

9-Você acredita que o estresse causado no ambiente de trabalho pode prejudicar seu desempenho e rendimento profissional.

10- A que fator você relaciona seu estresse no trabalho?

11- A que fator você relaciona seu estresse no trabalho?

12-Escolha uma das alternativas que você acredita que melhoraria sua qualidade de vida no trabalho:

13- Já precisou fazer uso de medicamentos para problemas relacionados ao estresse no trabalho?

14- Se sim, para qual problema?

15-No geral você está satisfeito com o clima organizacional da sua empresa? 